\title{
PENGARUH AKTIVASI KIMIA ARANG KAYU LABAN TERHADAP EFEKTIVITAS PEMURNIAN BIOGAS \& UNJUK KERJA GENERATOR-SET
}

\author{
Azmi Rianur ${ }^{1)}$, Abdul Ghofur ${ }^{2)}$ \\ 1,2Program Studi Teknik Mesin \\ Fakultas Teknik Universitas Lambung Mangkurat \\ JL. Akhmad Yani Km.36 Banjarbaru, Kalimantan Selatan, 70714 \\ Telp.0511-4772646, Fax 0511-4772646 \\ E-mail: azmirianur.ar96@gmail.com
}

\begin{abstract}
Abstak, Penelitian ini bertujuan untuk mengetahui pengaruh aktivasi kimia arang kayu laban terhadap efektivitas pemurnian biogas dan unjuk kerja generator-set. Penelitian ini dilakukan dengan mengalirkan biogas dari sanitary landfill menuju insulator pemurnian biogas yang berisi media adsorpsi berupa arang yang diaktivasi kimia baik itu dengan cairan $\mathrm{NaCl}$ ataupun $\mathrm{NaOH}$, kemudian biogas ditampung dalam tabung penyimpanan lalu dialirkan menuju chamber untuk dilakukan pembacaan kadar $\mathrm{CO}_{2}$ dan $\mathrm{CH}_{4}$ menggunakan gas analyzer. Dari penelitian ini didapatkan hasil sebagai berikut: Biogas tanpa pemurnian ( $\mathrm{CO}_{2}$ 2808,62 ppm dan $\mathrm{CH}_{4}$ 40,51 ppm), Biogas dengan pemurnian ( $\mathrm{CO}_{2}$ 2579,72 ppm, $\mathrm{CH}_{4}$ 42,43 ppm dan efektivitas sebesar 8,1\%), pada media adsorbsi teraktivasi $\mathrm{NaOH}\left(\mathrm{CO}_{2}\right.$ 1987,24 ppm, $\mathrm{CH}_{4} 62,76 \mathrm{ppm}$ dan efektivitas sebesar 29,2\%), pada media adsorbsi teraktivasi $\mathrm{NaCl}\left(\mathrm{CO}_{2} 1920,01 \mathrm{ppm}, \mathrm{CH}_{4}\right.$ 75,28 ppm dan efektivitas sebesar 31,6\%). Untuk hasil pengujian unjuk kerja generator-set menggunakan bahan bakar biogas yang telah dimurnikan dengan arang kayu laban teraktivasi kimia menggunakan $\mathrm{NaCl}$ yaitu untuk tanpa beban, didapatkan putaran sebesar 3484,87 rpm, suhu $130,1^{\circ} \mathrm{C}$, dan tegangan $240 \mathrm{~V}$ (stabil), dengan beban $350 \mathrm{~W}$ didapatkan putaran 2371,2 rpm, suhu 131,9 $9^{\circ}$, dan tegangan 150-240 V (tidak stabil), dengan beban $650 \mathrm{~W}$ didapatkan putaran 2256,5 rpm, suhu $145,7^{\circ} \mathrm{C}$, dan tegangan 100-200 V (tidak stabil).
\end{abstract}

Kata Kunci : Pemurnian Biogas, Arang Aktivasi Kimia, Arang Kayu Laban

\begin{abstract}
This study aims to determine the effect of laban charcoal chemical activation on the effectiveness of biogas purification and generator-set performance. This research is conducted by drain biogas from sanitary landfill to biogas purification insulator containing adsorption media in the form of chemical activated charcoal either with $\mathrm{NaCl}$ or NaOH liquid, then biogas is stored in the storage tube then flowed to chamber for the reading of $\mathrm{CO} 2$ and $\mathrm{CH} 4$ using gas analyzer. From this study the following results are obtained: Biogas without purification (CO2 2808.62 ppm and CH4 40.51 ppm), Biogas by purification (CO2 2579,72 ppm, CH4 42,43 ppm and effectiveness equal to 8,1\%), at activated NaOH activated medium (CO2 1987,24 ppm, CH4 62,76 ppm and effectiveness 29,2\%), NaCl activated adsorption medium (CO2 1920,01 ppm, CH4 75,28 ppm and effectiveness 31,6\%). For the result of generator-set performance test using biogas fuel that has been purified by charcoal of chemical activated charcoal using $\mathrm{NaCl}$ that is for no load, got round of 3484,87 rpm, temperature 130,10C, and voltage $240 \mathrm{~V}$ (stable), with $350 \mathrm{~W}$ load is 2371,2 rpm, temperature is 131,90C, and voltage 150-240 V (not stable), with load of $650 \mathrm{~W}$ obtained 2256,5 rpm rotation, temperature 145,70C, and voltage 100-200 V(not stable).
\end{abstract}

Keywords: Purification of Biogas, Chemical Activation Charcoal, Laban Wood Charcoal 


\section{PENDAHULUAN}

Biogas merupakan salah satu energi alternatif yang mulai berkembang dan dipertimbangkan sebagai energi masa depan karena sifatnya yang ramah lingkungan. Biogas berasal dari bahanbahan organik yang difermentasikan oleh aktivitas anaerobik dari bakteri metana yang didapatkan dengan cara metanogen seperti Methanobacterium $s p$. Metanogen sendiri adalah sebuah proses yang terakhir pada rantai mikroorganisme yang lebih rendah dekomposisi bahan organik dan kembali produk ke lingkungan. Dalam proses terbentuknya, biogas berlangsung dalam keadaan tertutup (Widhiyanuriyawan dan Nurkholis, 2013). Bakteri Metana beraktivitas secara anaerobik, sehingga biogas dapat menghasilkan gas-gas seperti $\mathrm{CO}_{2}, \mathrm{H}_{2} \mathrm{~S}, \mathrm{CH}_{4}$, dan gas lainnya. $\mathrm{CH}_{4}$ merupakan gas yang bisa dimanfaatkan sebagai bahan bakar, karena $\mathrm{CH}_{4}$ memiliki nilai kalor yang tinggi.

Teknologi pemurnian biogas telah dikembangkan dengan berbagai macam metode, diantaranya water scrubbing, chemical adsorption, membrane purification, dan adsorption technology. Teknologi adsorpsi pada biogas merupakan teknologi yang menggunakan prinsip adsorpsi penyerapan gas terutama $\mathrm{CO}_{2}$, sehingga persentase kandungan $\mathrm{CH}_{4}$ di dalam biogas akan meningkat (Iriani dan Ari, 2014).

\section{Biogas}

Biogas merupakan gas hasil dari dekomposisi suatu bahan organik secara anaerobik (tertutup dari udara bekas) untuk menghasilkan gas yang sebagian besar berupa metan (memiliki sifat mudah terbakar) dan karbondioksida. Proses dekomposisi anaerobik dibantu oleh sejumlah mikroorganisme, terutama bakteri metan. Suhu yang baik untuk proses fermentasi adalah suhu yang hangat yaitu berkisar $30^{\circ} \mathrm{C}-55^{\circ} \mathrm{C}$. Pada suhu tersebut mikroorganisme dapat bekerja secara optimal merombak bahan-bahan organik dan menghasilkan gas. Pembuatan biogas biasanya memanfaatkan kotoran ternak, misalnya sapi, kerbau, kuda, ayam, dll, akan tetapi bahan tersebut bisa diganti dengan sampah organik. Pemanfaatan sampah organik sangat bagus sebagai bahan dasar pembuatan biogas, mengingat sampah organik yang ada di Indonesia masih belum terkelola dengan baik (Jatmiko, 2015).

\section{Adsorpsi}

Adsorpsi dapat diartikan sebagai suatu proses yang terjadi akibat gas atau cairan terlarut yang terakumulasi pada suatu permukaan padatan ataupun cairan (adsorben) dan membentuk lapisan molekul atau atom (adsorbat). Istilah adsorpsi biasa digunakan untuk menggambarkan keberadaan suatu bahan tertentu (cairan atau padatan) dengan konsentrasi yang lebih tinggi pada permukaannya daripada di dalam medium fasa ruahnya. Secara singkat, adsorpsi menunjukan kelebihan konsentrasi pada permukaan. Adsorbat berarti zat yang terakumulasi pada suatu permukaan, sedangkan adsorben adalah suatu material permukaan padatan atau cairan (Ruthven, 1984).

\section{Kayu Laban (Vitex Pinnata L)}

Kayu laban adalah salah satu jenis tanaman hutan dengan sebaran pertumbuhan hampir di seluruh Indonesia yang meliputi Jawa, Madura, Sumatera, Kalimantan, Sulawesi, dan Pulau Bangka. Kayu laban merupakan jenis pohon yang mudah tumbuh dan dapat ditanam pada berbagai jenis tanah yang memiliki daya tahan terhadap kebakaran dan banyak tumbuh di hutan sekunder. Pada tahun 1994 tanaman laban telah dibudidayakan oleh pusat pengembangan teknologi arang terpadu di atas tanah seluas 1,4 Ha. Sehingga sejak tahun 1997 telah berproduksi yang dimanfaatkan sebagai bahan baku arang (Kasmawarni, 2013). 


\begin{abstract}
Aktivasi Arang
Aktivasi merupakan suatu perlakuan terhadap arang dengan tujuan untuk memperbesar pori-pori arang yaitu dengan cara memecah ikatanikatan hidrokarbon atau dengan cara mengoksidasi molekul-molekul yang terdapat pada permukaan arang sehingga arang mengalami perubahan sifat, baik itu kimia maupun fisika. Luas permukaan arang akan bertambah besar dan berpengaruh terhadap daya adsorpsinya (Sembiring, 2003). Aktivasi kimia merupakan proses pemutusan rantai karbon dari senyawa organik dengan pemakaian bahan-bahan kimia (Sembiring, 2003). Aktivasi kimia biasanya menggunakan bahan-bahan pengaktif yang biasa disebut bahan aktivator seperti $\mathrm{CaCl}_{2}, \mathrm{MgCl}_{2}, \mathrm{ZnCl}_{2}$, $\mathrm{NaOH}, \mathrm{Na}_{2} \mathrm{CO}_{3}$, dan $\mathrm{NaCl}$.
\end{abstract}

\section{METODE PENELITIAN}

Penelitian ini dilaksanakan di TPA Cahaya Kencana Kecamatan Karang Intan Kabupaten Banjar. Penelitian ini memerlukan waktu \pm 5 bulan.

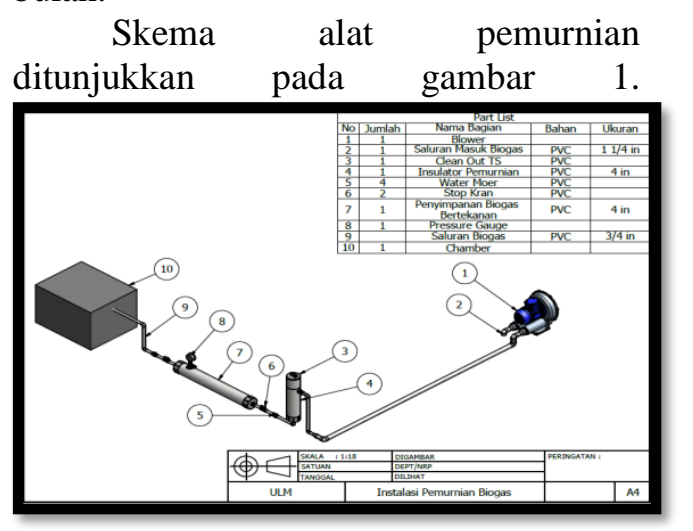

Gambar 1. Skema Alat Pemurnian Biogas

\section{Bahan Penelitian}

1. Biogas berasal dari TPA Cahaya Kencana.

2. Arang kayu laban dengan ukuran serbuk 40 mesh.

3. Bahan Aktivator cairan $\mathrm{NaOH}$

4. Bahan aktivator cairan $\mathrm{NaCl}$

\section{Teknik Pengumpulan Data}

Metode penelitian yang digunakan pada penelitian ini yaitu metode library research (studi literatur), yaitu dengan mempelajari literaturliteratur yang berkaitan dengan penelitian ini, dan menggunakan metode eksperimen secara langsung yaitu dengan cara menyelidiki hubungan sebab-akibat dari beberapa kondisi perlakuan dengan menggunakan alat peraga atau alat pengujian.

Adapun variabel-variabel dalam penelitian ini terbagi dalam tiga variabel, yaitu:

1. Variabel tetap

Variabel tetap yaitu variabel yang selama proses penelitian dikondisikan sama dan diasumsikan konstan. Adapun veriabel tetap dalam penelitan ini antara lain :

- Berat sampel arang 500 gram.

- Ukuran serbuk yang digunakan adalah 40 mesh.

- Arang yang digunakan yaitu arang kayu laban.

- Bahan bakar Ignite Generator-Set yaitu Pertalite.

2. Variabel terikat

Variabel terikat, yaitu variabel yang menjadi tujuan utama dari penelitian, di mana tujuan utama dari penelitian adalah menjelaskan variabel terikat. Yang menjadi variabel terikat dari penelitian ini adalah kandungan $\mathrm{CO}_{2}$ dan $\mathrm{CH}_{4}$ pada biogas sebelum dan setelah dilakukan proses pemurnian dengan metode adsorpsi.

3. Variabel bebas

Variabel bebas, yaitu kondisi yang dikehendaki oleh peneliti, yang mana di dalam proses penelitian akan mempengaruhi variabel terikat. Dalam penelitian ini yang merupakan variabel bebas adalah variasi aktivator pada arang kayu laban berupa cairan $\mathrm{NaCl}$ dan $\mathrm{NaOH}$. 


\section{Prosedur Pelaksanaan Penelitian}

1. Penumbukan Arang

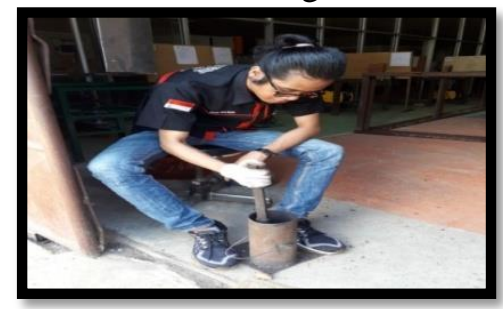

Gambar 2. Penumbukan Arang

2. Pengayakan Arang

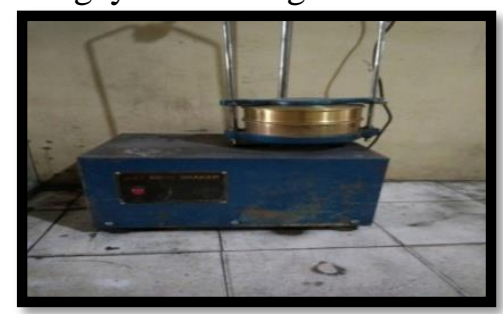

Gambar 3. Pengayakan Arang

3. Penimbangan Arang

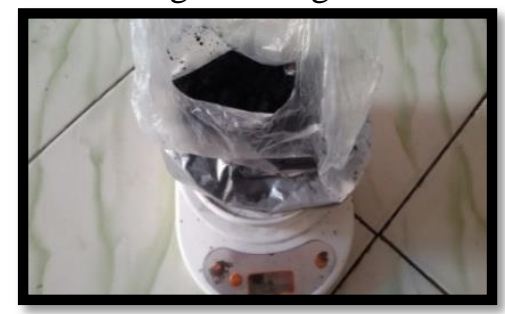

Gambar 4. Penimbangan Arang

4. Aktivasi Arang

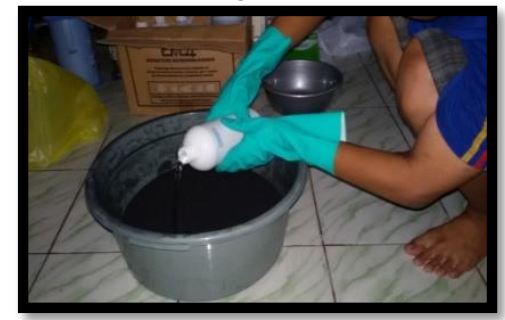

Gambar 5. Penuangan Bahan aktivator

5. Pemurnian Biogas

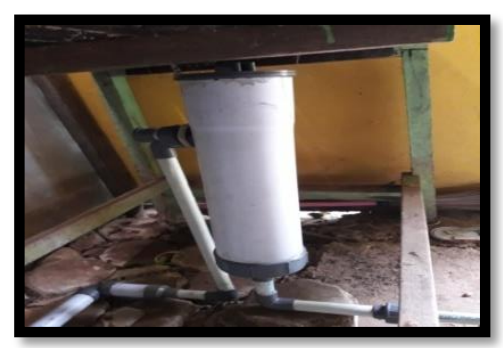

Gambar 6. Insulator ( Alat Pemurnian Biogas)
6. Penyimpanan Biogas

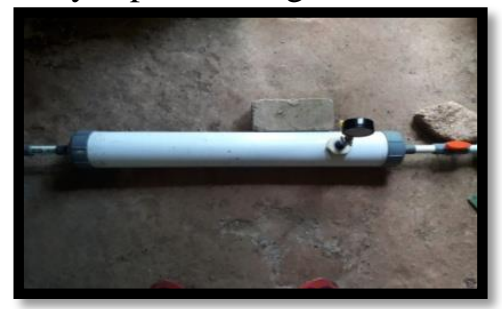

Gambar 7. Tabung Penyimpanan Biogas

7. Pengujian $\mathrm{CO}_{2}$ dan $\mathrm{CH}_{4}$

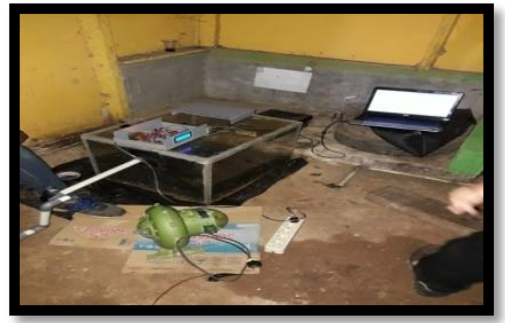

Gambar 8. Pengujian Kadar $\mathrm{CO}_{2}$ dan $\mathrm{CH}_{4}$

8. Pengujian Unjuk Kerja Generator-Set

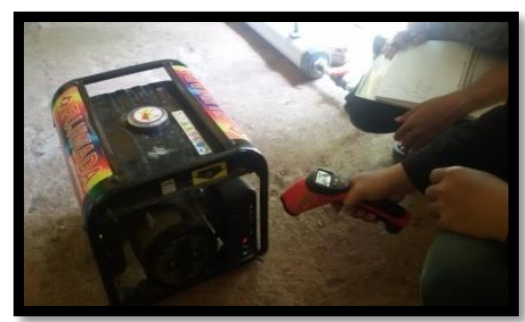

Gambar 9. Pengukuran Suhu pada Generator-Set

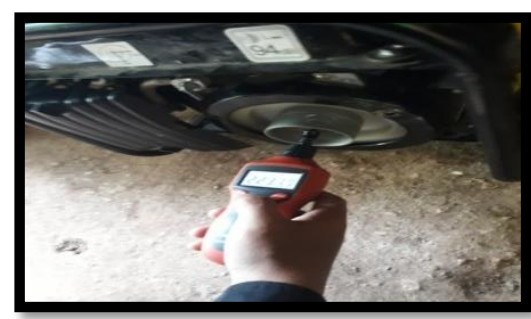

Gambar 10. Pengukuran putaran pada Generator-Set

\section{HASIL DAN PEMBAHASAN}

Pengujian ini dilakukan di TPA Cahaya Kencana Kecamatan Karang Intan Kabupaten Banjar. Pengujian ini dilakukan dengan tujuan mengetahui pengaruh aktivasi kimia arang kayu laban terhadap efektivitas pemurnian 
biogas dan unjuk kerja generator-set. Hasil Pengujian ditunjukkan pada Tabel 1, Tabel 2, Tabel 3, Tabel 4, Tabel 5, dan Tabel 6.

Tabel 1. Hasil Pengujian Kadar Karbondioksida

\begin{tabular}{|c|c|c|c|}
\hline No & Perlakuan & $\begin{array}{c}\mathrm{CO}_{2} \\
(\mathrm{ppm})\end{array}$ & $\begin{array}{l}\text { Rata - } \\
\text { Rata } \\
(\mathrm{ppm})\end{array}$ \\
\hline \multirow{3}{*}{1} & \multirow{3}{*}{$\begin{array}{c}\text { Tanpa } \\
\text { Perlakuan }\end{array}$} & 2641,44 & \multirow{3}{*}{2808,62} \\
\hline & & 2755,85 & \\
\hline & & 3028,55 & \\
\hline \multirow{3}{*}{2} & \multirow{3}{*}{$\begin{array}{l}\text { Arang } \\
\text { Laban } \\
\text { Tanpa } \\
\text { Aktivasi }\end{array}$} & 2584,78 & \multirow{3}{*}{2579,72} \\
\hline & & 2438,64 & \\
\hline & & 2715,74 & \\
\hline \multirow{3}{*}{3} & Arang & 2017,01 & \multirow{3}{*}{1920,01} \\
\hline & \multirow{2}{*}{$\begin{array}{c}\text { Dengan } \\
\text { Aktivator } \\
\mathrm{NaCl}\end{array}$} & 1884,28 & \\
\hline & & 1858,75 & \\
\hline \multirow{4}{*}{4} & \multirow{4}{*}{$\begin{array}{c}\text { Arang } \\
\text { Laban } \\
\text { Dengan } \\
\text { Aktivator } \\
\mathrm{NaOH}\end{array}$} & 2016,54 & \multirow{4}{*}{1987,24} \\
\hline & & 2020,88 & \\
\hline & & & \\
\hline & & 1924,30 & \\
\hline
\end{tabular}

Tabel 2. Hasil Pengujian Kadar Metana

\begin{tabular}{|c|c|c|c|}
\hline No. & Perlakuan & $\begin{array}{c}\mathrm{CH}_{4} \\
(\mathrm{ppm})\end{array}$ & $\begin{array}{c}\text { Rata - } \\
\text { Rata } \\
\text { (ppm) }\end{array}$ \\
\hline \multirow{3}{*}{1} & \multirow{3}{*}{$\begin{array}{c}\text { Tanpa } \\
\text { Perlakuan }\end{array}$} & 41,95 & \multirow{3}{*}{40,51} \\
\hline & & 39,77 & \\
\hline & & 39,83 & \\
\hline \multirow{3}{*}{2} & \multirow{3}{*}{$\begin{array}{l}\text { Arang } \\
\text { Laban } \\
\text { Tanpa } \\
\text { Aktivasi }\end{array}$} & 43,41 & \multirow{3}{*}{42,43} \\
\hline & & 41,11 & \\
\hline & & 42,76 & \\
\hline \multirow{3}{*}{3} & \multirow{3}{*}{$\begin{array}{c}\text { Arang } \\
\text { Laban } \\
\text { dengan } \\
\text { Aktivator } \\
\mathrm{NaCl}\end{array}$} & 62,04 & \multirow{3}{*}{75,28} \\
\hline & & 87,95 & \\
\hline & & 75,84 & \\
\hline \multirow{3}{*}{4} & \multirow{3}{*}{$\begin{array}{c}\text { Arang } \\
\text { Laban } \\
\text { dengan } \\
\text { Aktivator } \\
\mathrm{NaOH}\end{array}$} & 35,88 & \multirow{3}{*}{62,76} \\
\hline & & 69,62 & \\
\hline & & 82,77 & \\
\hline
\end{tabular}

\section{Efektivitas Penyerapan $\mathrm{CO}_{2}$ Pada Biogas Setelah Proses Pemurnian}

Efektivitas digunakan untuk mengetahui hubungan keberhasilan $\mathrm{CO}_{2}$ yang terserap oleh media pemurnian menggunakan arang kayu laban dengan target / tujuan yang ditetapkan. Asumsi bahwa $\mathrm{CO}_{2}$ yang ingin dihilangkan adalah sebesar $100 \%$, dengan besarnya kandungan $\mathrm{CO}_{2}$ awal. Sehingga didapatkan persamaan sebagai berikut: Efektivitas $=\frac{\mathrm{CO}_{2} \text { Awal }-\mathrm{CO}_{2} \text { Akhir }}{\mathrm{CO}_{2} \mathrm{Awal}} \times 100 \%$ 
Tabel 3. Efektivitas Penyerapan $\mathrm{CO}_{2}$

\begin{tabular}{|c|c|c|}
\hline No. & Perlakuan & $\begin{array}{c}\text { Efektivitas } \\
\text { Penyerapan } \\
\mathrm{CO}_{2}(\%)\end{array}$ \\
\hline 1. & Tanpa Aktivasi & 8,1 \\
\hline 2. & $\begin{array}{c}\text { Aktivasi Kimia } \\
\text { Dengan } \mathrm{NaCl}\end{array}$ & 31,6 \\
\hline 3. & $\begin{array}{c}\text { Aktivasi Kimia } \\
\text { Dengan } \mathrm{NaOH}\end{array}$ & 29,2 \\
\hline
\end{tabular}

Efektivitas Kenaikan $\mathbf{C H}_{4}$ Pada Biogas Setelah Proses Pemurnian

Efektivitas digunakan untuk mengetahui hubungan keberhasilan kenaikan $\mathrm{CH}_{4}$ pemurnian menggunakan arang kayu labandengan target / tujuan yang ditetapkan.asumsi bahwa $\mathrm{CH}_{4}$ yang ingin dinaikan adalah sebesar 100\%, oleh karena itu target / tujuan sama dengan besarnya kandungan $\mathrm{CH}_{4}$ akhir. Sehingga didapatkan persamaan sebagai berikut.

Efektivitas $=\frac{\mathrm{CH}_{4} \text { Akhir }-\mathrm{CH}_{4} \text { Awal }}{\mathrm{CH}_{4} \text { Akhir }} \times 100 \%$

Tabel 4. Efektivitas Kenaikan Volume Metana

\begin{tabular}{|c|c|c|}
\hline No. & Perlakuan & $\begin{array}{c}\text { Efektivitas } \\
\text { Penyerapan } \\
\mathrm{CO}_{2}(\%)\end{array}$ \\
\hline 1. & Tanpa Aktivasi & 8,1 \\
\hline 2. & $\begin{array}{c}\text { Aktivasi Kimia } \\
\text { Dengan } \mathrm{NaCl}\end{array}$ & 31,6 \\
\hline 3. & $\begin{array}{c}\text { Aktivasi Kimia } \\
\text { Dengan } \mathrm{NaOH}\end{array}$ & 29,2 \\
\hline
\end{tabular}

Tabel 5. Hasil Pengujian Unjuk kerja Generator-Set Menggunakan Bahan

Bakar Pertalite

\begin{tabular}{|c|c|c|c|c|}
\hline \multirow{2}{*}{ No. } & \multirow{2}{*}{$\begin{array}{c}\text { Variabel } \\
\text { Pengujian }\end{array}$} & \multicolumn{3}{|c|}{ Beban } \\
\cline { 3 - 5 } & & OW & $\begin{array}{c}350 \\
\text { W }\end{array}$ & $\begin{array}{c}650 \\
\text { W }\end{array}$ \\
\hline 1 & $\begin{array}{c}\text { Putaran } \\
\text { (rpm) }\end{array}$ & 3143,67 & $\begin{array}{c}2313, \\
87\end{array}$ & $\begin{array}{c}2229 \\
47\end{array}$ \\
\hline 2 & $\begin{array}{c}\text { Suhu Gas } \\
\text { Buang } \\
\left({ }^{\circ} \mathrm{C}\right)\end{array}$ & 92,17 & $\begin{array}{c}113,8 \\
7\end{array}$ & 136,1 \\
\hline 3 & $\begin{array}{c}\text { Tegangan } \\
(\mathrm{V})\end{array}$ & $\begin{array}{c}220 \\
(\text { Stabil })\end{array}$ & $\begin{array}{c}200 \\
(\text { Stabi } \\
\text { l) }\end{array}$ & $\begin{array}{c}200 \\
(\text { Stabi } \\
\text { I) }\end{array}$ \\
\hline
\end{tabular}

Tabel 6. Hasil Pengujian Unjuk Kerja Generator-Set Menggunakan Bakar Bakar Biogas Hasil Pemurnian Arang Kayu laban Aktivasi Kimia dengan Aktivator $\mathrm{NaCl}$

\begin{tabular}{|c|c|c|c|c|}
\hline \multirow{2}{*}{ No. } & \multirow{2}{*}{$\begin{array}{l}\text { Variabel } \\
\text { Pengujian }\end{array}$} & \multicolumn{3}{|c|}{ Beban } \\
\hline & & $0 \mathrm{~W}$ & $350 \mathrm{~W}$ & $650 \mathrm{~W}$ \\
\hline 1 & $\begin{array}{c}\text { Putaran } \\
\text { (rpm) }\end{array}$ & 3484,87 & 2371,2 & 2256,5 \\
\hline 2 & $\begin{array}{c}\text { Suhu Gas } \\
\text { Buang } \\
\left({ }^{\circ} \mathrm{C}\right)\end{array}$ & 130,1 & 131,9 & 145,7 \\
\hline 3 & $\begin{array}{c}\text { Tegangan } \\
\text { (V) }\end{array}$ & $\begin{array}{c}240 \\
\text { (Stabil) }\end{array}$ & $\begin{array}{c}150- \\
240 \\
\text { (Tidak } \\
\text { Stabil) }\end{array}$ & $\begin{array}{c}100- \\
200 \\
\text { (Tldak } \\
\text { Stabil) }\end{array}$ \\
\hline
\end{tabular}

\section{PEMBAHASAN}

Dari hasil pengujian didapatkan hasil kadar karbondioksida $\left(\mathrm{CO}_{2}\right)$ \& gas metana $\left(\mathrm{CH}_{4}\right)$ pada biogas, serta putaran (rpm), tegangan $(\mathrm{V})$, dan suhu gas buang $\left({ }^{\circ} \mathrm{C}\right)$ pada Generator-Set. Data hasil pengujian yang telah didapatkan kemudian dibahas dalam bentuk grafik. Berikut ini merupakan grafik-grafik data dari hasil pengujian: 


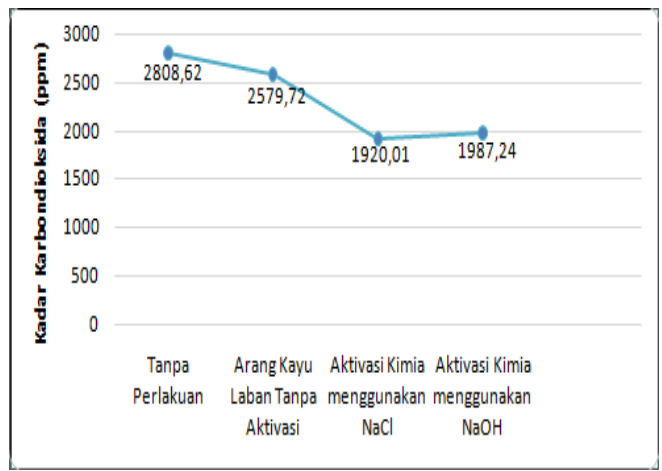

Gambar 11. Grafik hubungan Kadar Karbondioksida Dengan Perlakuan Pada Biogas

Dari Gambar 11 dapat dilihat bahwa kadar karbondioksida $\left(\mathrm{CO}_{2}\right)$ tertinggi adalah 2808,62 ppm yaitu pada biogas tanpa perlakuan dan kadar karbondioksida terendah adalah 1920,01 ppm yaitu pada biogas dengan perlakuan arang kayu laban teraktivasi kimia dengan bahan aktivator $\mathrm{NaCl}$. Dari grafik di atas dapat dilihat bahwa bahan aktivator $\mathrm{NaCl}$ lebih baik dalam menyerap Karbondioksida dibandingkan dengan bahan aktivator $\mathrm{NaOH}$. Hal Ini dikarenakan larutan $\mathrm{NaCl}$ memiliki sifat sebagai senyawa dehydrating agent yang mana pada proses karbonisasi dapat membatasi pembentukan tar.

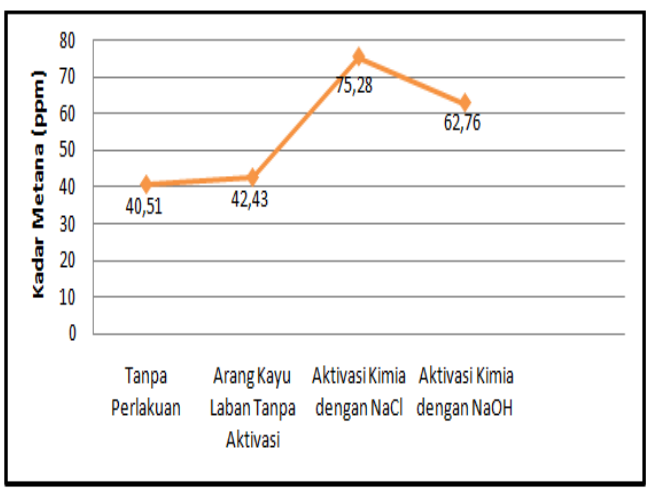

Gambar 12. Grafik Hubungan Kadar Gas Metana Dengan Perlakuan Pada Biogas

Dari Gambar 12 dapat dilihat bahwa kadar gas metana $\left(\mathrm{CH}_{4}\right)$ tertinggi adalah 75,28 ppm yaitu pada biogas dengan perlakuan arang kayu laban yang diaktivasi secara Kimia dengan bahan aktivator $\mathrm{NaCl}$ dan kadar karbondioksida terendah adalah 40,51 ppm yaitu pada biogas tanpa perlakuan. Dari grafik diatas dapat dilihat juga bahwa kadar gas metana $\left(\mathrm{CH}_{4}\right)$ yang lebih baik diperoleh melalui pemurnian biogas dengan arang hasil aktivasi kimia menggunakan bahan aktivator $\mathrm{NaCl}$ dibandingkan dengan aktivasi kimia menggunakan bahan aktivator $\mathrm{NaOH}$. Hal ini membuktikan bahwa dalam konsep pemurnian biogas, apabila $\mathrm{CO}_{2}$ terserap oleh adsorben maka secara otomatis $\mathrm{CH}_{4}$ akan mengalami kenaikan volume.

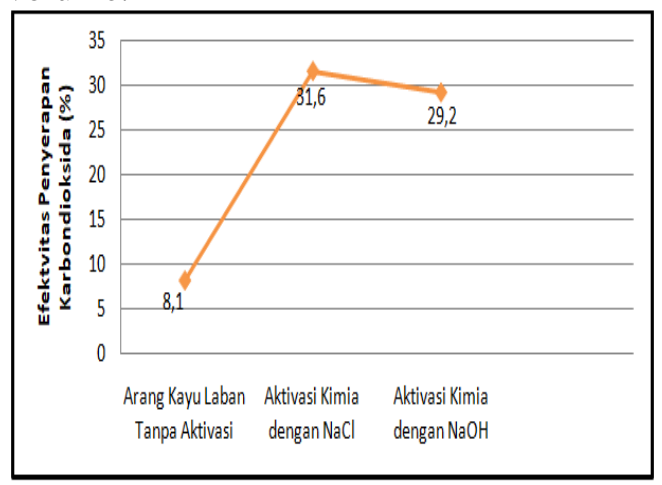

Gambar 13. Grafik Hubungan Efektivitas Penyerapan $\mathrm{CO}_{2} \quad$ Pada Pemurnian Biogas Dengan Perlakuan Pada Biogas

Dari Gambar 13 dapat dilihat bahwa efektivitas tertinggi yang didapat pada saat pengujian adalah $31,6 \%$ yaitu pada biogas dengan perlakuan arang kayu laban yang diaktivasi secara kimia dengan menggunakan bahan aktivator $\mathrm{NaCl}$ dan efektivitas terendah yang didapat pada saat pengujian adalah 8,1 $\%$ yaitu pada biogas tanpa perlakuan. Dari grafik di atas dapat dilihat bahwa efektivitas pemurnian biogas dengan bahan aktivator $\mathrm{NaCl}$ lebih baik dibandingkan $\mathrm{NaOH}$. Hal Ini dikarenakan larutan $\mathrm{NaCl}$ terdapat sifat senyawa dehydrating agent di mana pada saat proses karbonisasi berlangsung dapat membatasi pembentukan tar. Tar yang terbentuk pada saat proses karbonisasi ini dapat menutupi pori-pori yang terbentuk sehingga luas permukaan spesifiknya mengecil, dengan demikian semakin 
sedikit tar yang terbentuk, maka semakin besar pula luas permukaan spesifik yang terbentuk

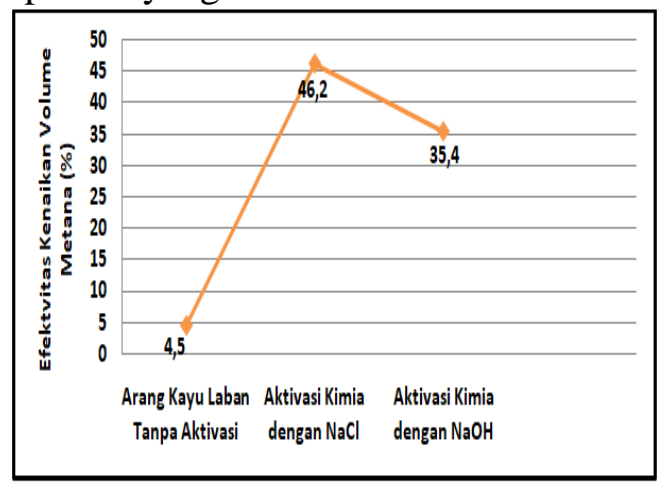

Gambar 14. Grafik Hubungan Kenaikan Volume $\mathrm{CH}_{4}$ Pada Pemurnian Biogas Dengan Perlakuan Pada Biogas

Dari Gambar 14 dapat dilihat bahwa efektivitas tertinggi kenaikan volume $\mathrm{CH}_{4}$ yang didapat pada saat pengujian adalah $46,2 \%$ yaitu pada biogas dengan perlakuan arang kayu laban yang diaktivasi secara kimia dengan menggunakan bahan aktivator $\mathrm{NaCl}$ dan efektivitas terendah yang didapat pada saat pengujian adalah 4,5 $\%$ yaitu pada biogas tanpa perlakuan. Hal ini dikarenakan Efektivitas kenaikan volume $\mathrm{CH}_{4}$ berbanding lurus dengan efektivitas penyerapan $\mathrm{CO}_{2}$ pada pemurnian biogas, semakin naik persentase kandungan $\mathrm{CH}_{4}$ pada biogas yang telah dimurnikan, semakin besar pula efektivitas penyerapan kadar $\mathrm{CO}_{2}$ yang dapat dihasilkan pada sistem pemurnian biogas.

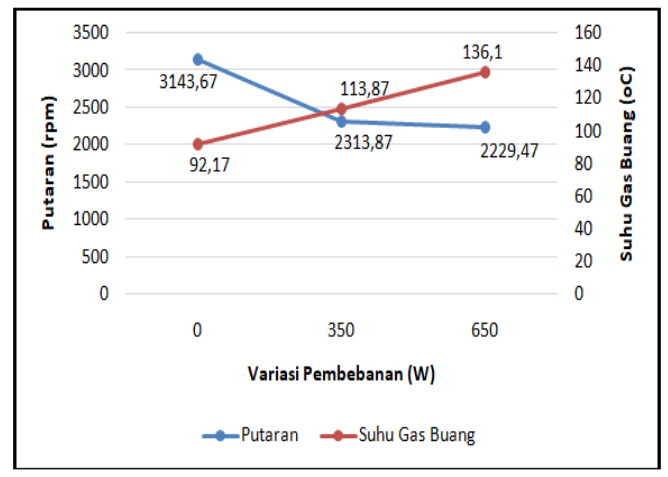

Gambar 15. Grafik Hubungan Unjuk Kerja Generator-Set Menggunakan Bahan Bakar Pertalite Terhadap Penambahan Pembebanan

Dari Gambar 15 dapat dilihat bahwa nilai putaran tertinggi adalah 3143,67 rpm yaitu pada pembebanan 0 $\mathrm{W}$ dan nilai putaran terendah adalah 2229,47 rpm yaitu pada pembebanan $650 \mathrm{~W}$. Dari grafik diatas dapat dilihat juga bahwa nilai putaran mengalami penurunan seiring dengan penambahan beban pada Generator-Set yang diuji. Sedangkan untuk suhu gas buang, nilai suhu gas buang tertinggi adalah $136,1^{\circ} \mathrm{C}$ yaitu pada pembebanan $650 \mathrm{~W}$ dan nilai suhu gas buang terendah adalah 92,17 ${ }^{\circ} \mathrm{C}$ pada pembebanan $0 \mathrm{~W}$ (tanpa beban).

Dari Gambar 15 diatas pula dapat dilihat bahwa nilai suhu gas buang mengalami peningkatan seiring dengan penambahan beban pada Generator-Set yang diuji. Dari tabel 5, dapat dilihat juga bahwa Generator-Set menggunakan bahan bakar pertalite menunjukan stabilitas tegangan yang baik dimana tegangan yang dihasilkan tetap stabil pada saat tanpa beban maupun saat diberikan pembebanan $350 \mathrm{~W}$ maupun $650 \mathrm{~W}$.

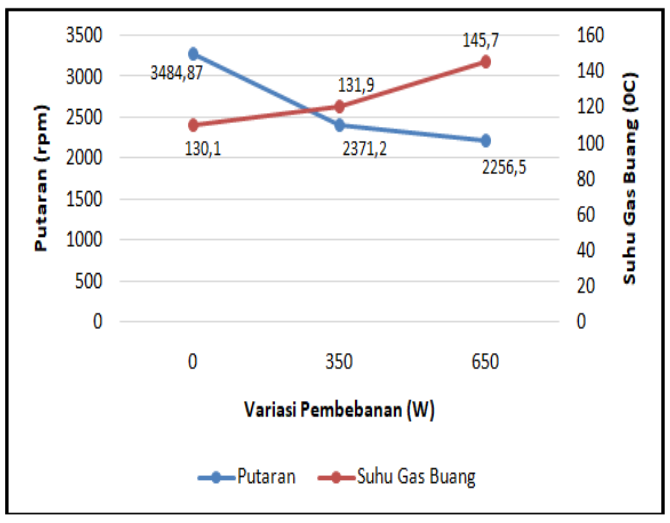

Gambar 16. Grafik Hubungan Unjuk Kerja Generator-Set Menggunakan Bahan Bakar Biogas Hasil Pemurnian Terhadap Penambahan Pembebanan

Dari Gambar 16 dapat dilihat bahwa nilai putaran tertinggi adalah $3484,87 \mathrm{rpm}$ yaitu pada pembebanan 0 Watt dan nilai putaran terendah adalah 
2256,5 rpm yaitu pada pembebanan 650 Watt. Dari grafik diatas dapat dilihat juga bahwa nilai putaran mengalami penurunan yang berbanding terbalik dengan penambahan beban pada Generator-Set yang diuji. Sedangkan untuk suhu gas buang, nilai suhu gas buang tertinggi adalah $145,7{ }^{\circ} \mathrm{C}$ yaitu pada pembebanan 650 Watt dan nilai suhu gas buang terendah adalah 130,1 ${ }^{0} \mathrm{C}$. Dari grafik diatas dapat dilihat bahwa nilai suhu gas buang mengalami peningkatan seiring dengan penambahan beban pada Generator-Set yang diuji.

Dari tabel 6, dapat dilihat juga bahwa Generator-Set menggunakan bahan bakar biogas hasil pemurnian menunjukan stabilitas tegangan yang kurang baik dimana tegangan yang dihasilkan tetap stabil pada saat tanpa beban tetapi tidak stabil saat diberi pembebanan

\section{KESIMPULAN}

Adapun kesimpulan dari penelitian ini adalah sebagai berikut:

1. Kadar karbondioksida $\left(\mathrm{CO}_{2}\right)$ tertinggi adalah 2808,62 ppm yaitu pada biogas tanpa perlakuan, sedangkan kadar karbondioksida $\left(\mathrm{CO}_{2}\right)$ terendah adalah 1920,01 ppm yaitu pada biogas hasil pemurnian arang yang diaktivasi dengan $\mathrm{NaCl}$, untuk hasil karbondioksida menggunakan aktivator $\mathrm{NaOH}$ adalah 1987,24 ppm. Untuk efektivitas pemurnian biogas terendah adalah $8,1 \%$ yaitu pada pemurnian tanpa aktivasi sedangkan efektivitas tertinggi adalah 31,6\% yaitu pada biogas hasil pemurnian arang kayu laban dengan aktivator $\mathrm{NaCl}$, dan untuk efektivitas penyerapan $\mathrm{CO}_{2}$ dengan aktivator $\mathrm{NaOH}$ adalah $29,2 \%$.

2. Kadar gas metana $\left(\mathrm{CH}_{4}\right)$ tertinggi adalah 75,28 ppm yaitu pada biogas hasil pemurnian menggunakan arang dengan aktivator $\mathrm{NaCl}$, sedangkan kadar gas metana $\left(\mathrm{CH}_{4}\right)$ terendah adalah 40,51 ppm yaitu pada biogas tanpa perlakuan, dan untuk hasil pemurnian dengan arang kayu laban menggunakan aktivator $\mathrm{NaOH}$ adalah $62,76 \mathrm{ppm}$.

3. Unjuk kerja Generator-Set menggunakan bahan bakar pertalite menunjukan stabilitas tegangan yang baik dimana tegangan tetap stabil saat tanpa beban maupun saat diberikan beban sedangkan Unjuk kerja Generator-Set menggunakan bahan bakar biogas hasil pemurnian menggunakan arang kayu laban yang diaktivasi dengan aktivator $\mathrm{NaCl}$ menunjukan stabilitas tegangan yang kurang baik dimana tegangan tetap stabil saat tanpa beban tetapi tidak stabil saat diberikan beban. Ketidakstabilan ini disebabkan karena kurangnya suplai gas dari Sanitary Landfill yang dikarenakan cuaca yang cukup terik pada saat pengujian berlangsung.

\section{DAFTAR PUSTAKA}

Iriani, Purwinda, Ari Heryadi. 2014. Pemurnian Biogas Melalui Kolom Beradsorben Karbon Aktif. Sigma-Mu. Vol. 6 N0. 2.

Jatmiko, Sigit. 2015. Karakteristik

Thermal Biogas Yang

Difurifikasi Larutan $\mathrm{KOH} 4$

(Empat) Molaritas

Dibandingkan Dengan Biogas

Tanpa Purifikasi. Skripsi. Jember : Universitas Jember.

Kasmawarni. 2013. Proses Aktivasi Arang Kayu Laban (Vitex Pinnata L.) Dengan Cara Pemanasan Pada Suhu Tinggi. Jurnal Litbang Industri. Vol. 3 No. 2 : 117-124.

Ruthven, Douglas M. 1984. Principles of Adsorption and Adsorption Processes. Kanada : Published Simultaneously.

Widhiyanuriyawan, Denny, Nurkholis Hamidi. 2013. Variasi Temperatur Pemanasan Zeolit Alam-NaOH Untuk Pemurnian Biogas. Jurnal Energi dan Manufaktur. Vol. 6 No.1 : 53-63 